\title{
Natal Dispersal and Sociality of Young Galapagos Hawks on Santiago Island
}

\author{
Jose Luis Rivera ${ }^{*}, 1,2$, F. Hernan Vargas ${ }^{2}$ and Patricia G. Parker ${ }^{1}$ \\ ${ }^{1}$ Department of Biology, University of Missouri-St. Louis, One University Boulevard, St. Louis, MO 63121-4400, USA \\ ${ }^{2}$ The Peregrine Fund, 5668 West Flying Hawk Lane, Boise, Idaho 83709, USA
}

\begin{abstract}
The Galapagos Hawk (Buteo galapagoensis) is the only diurnal resident raptor in the Galapagos Archipelago, where it exhibits a cooperatively polyandrous mating system. Before breeding, young hawks spend 3-4 years as nonterritorial floaters. Individuals in this age class are highly gregarious on the island of Santiago. Here we examine patterns in natal dispersal and ask whether they appear to develop social affiliations with particular individuals during their juvenile years. Using data collected between 1998 and 2009 from a banded population of 25 territorial groups, we found that natal dispersal is more likely to be to territories adjacent to natal territories than expected by chance, and is not significantly related to the specific type of vegetation of the natal territory. We found no evidence of social affiliations or stable coalitions among particular juveniles; instead they moved in opportunistic aggregations.
\end{abstract}

Keywords: Buteo galapagoensis, coalitions, floater, natal dispersal, polyandry.

\section{INTRODUCTION}

Natal dispersal can be defined as the movement of an individual from its place of birth to the place where it reproduces $[1,2]$. These movements in turn determine the genetic structure of the population, gene flow and colonization. Studies of natal dispersal in temperate raptors show significant patterns in natal dispersal related to age [3], habitat characteristics [4, 5], sex [6], brood size and sociality $[7,8]$ and breeding density [9]. The few studies on tropical raptors (e.g. van Balen [10]; Rafanomezantsoa et al. [11]; Nijman and van Balen [12]) found that habitat quality seems to be among the most important factors determining natal dispersal patterns. In general, birds effectively choose specific habitats as they disperse [13], and their preferences may be genetically determined or acquired during development [14]; either way, the natal habitat of the disperser is expected to resemble the breeding habitat of the adult bird. In addition, natal dispersal patterns can affect species distribution and chances of colonization [15], a major factor in an island ecosystem.

The Galapagos Hawk (Buteo galapagoensis) is endemic to the Galapagos Islands and is a cooperatively polyandrous breeder [16, 17]. After fledging, young hawks spend 3-4 years as non-breeding "floaters" without territories [18]. Their biology during these wandering years remains largely unknown. The natal dispersal distance (measured from the natal territory to first breeding territory) has not been estimated and nothing is known about the selection of settlement areas by first-time breeders.

Galapagos hawks are highly social animals [16] and it is common to see large aggregations of floaters on the island of

*Address correspondence to this author at the Department of Biology, University of Missouri-St. Louis, One University Boulevard, St. Louis, MO 63121-4400, USA; Tel: (314) 516-7276; Fax: (314) 516-6233; E-mail: jose.rivera@umsl.edu
Santiago [18], made up mainly of juveniles. Association patterns between related individuals and movements in "coalitions" (e.g. group of closely associated individuals that perform aspects of their lives together) have been documented for Black Vultures [19, 20], Egyptian Vultures [21] and marginally in Long-eared Owls [22]. Being social as a floater could enhance survivorship of juveniles, by helping to overwhelm defenses by territorial adults and thus conferring feeding advantages. It is also possible that coalitions formed as juveniles may persist until adulthood and/or breeding group formation in this polyandrous species. Juveniles are the "pipeline" source for breeding adults, crucial to the dynamics of any population [23].

In this paper we focused on natal dispersal and sociality of a banded population of Galapagos Hawks studied on Santiago Island between 1998 and 2009. First, we asked whether the 3-4 year "floating" period of juveniles: (1) ends in a breeding territory neighboring the natal territory; and (2) ends in nesting areas with vegetation types resembling the natal territory. Then, looking to the social structure of these coalitions of floaters, we asked if the observed groups are composed of: (3) stable coalitions involving particular individuals, or (4) individuals aggregating opportunistically.

\section{METHODS}

\section{Study Area}

Santiago Island is located in the center of the Galapagos archipelago, reaching $907 \mathrm{~m}$ elevation with an area of 585 $\mathrm{Km}^{2}$, and is one of the largest islands not inhabited by humans [24]. Since 1998, 25 hawk territories have been studied in James Bay $(58,465 \mathrm{ha})$ located in the northwestern part of Santiago. This site has three clearly recognized vegetation types: (1) an arid zone, characterized by sparse vegetation dominated by Palo Santo trees (Bursera graveolens), various shrubs, Opuntia cactus and seasonal 


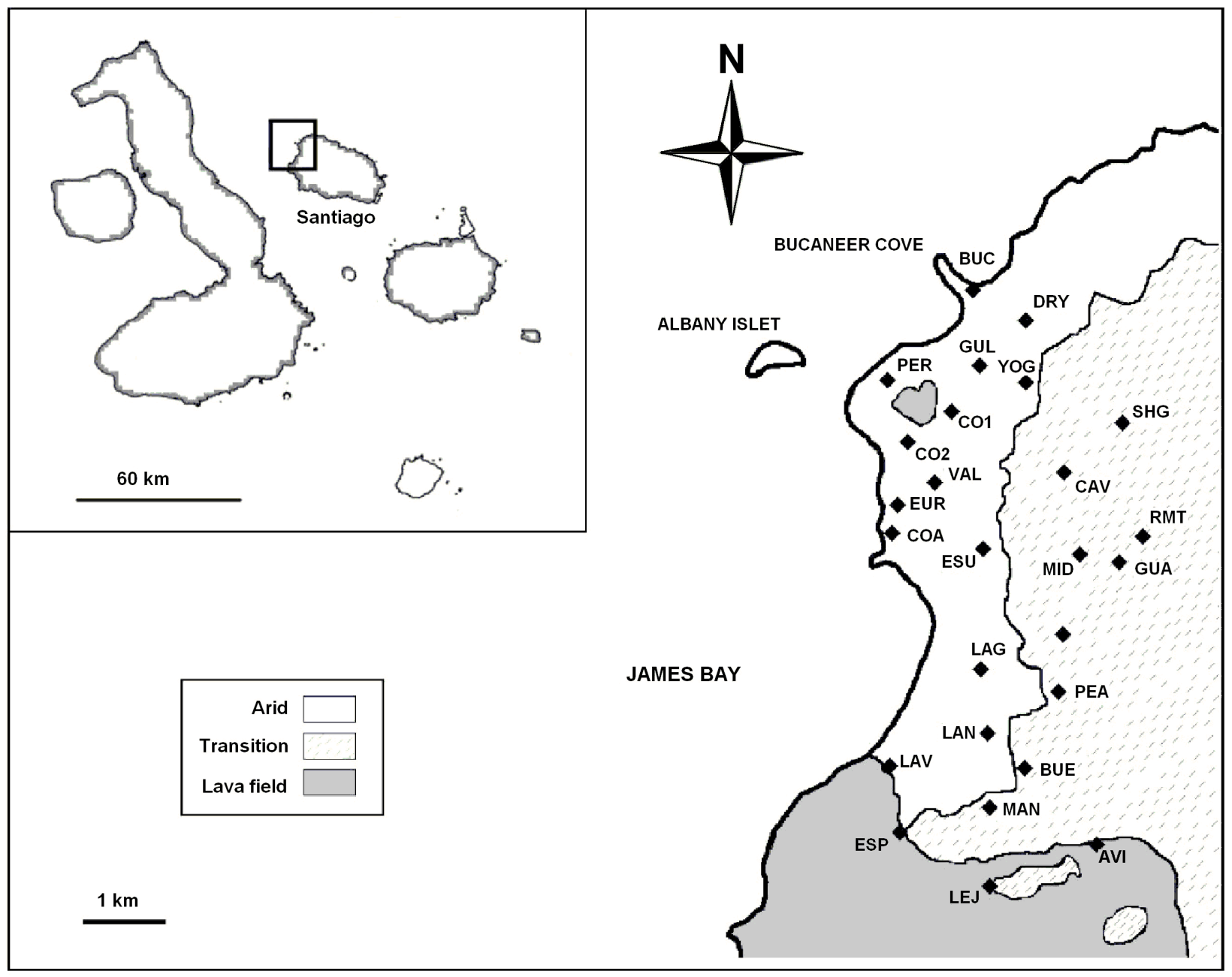

Fig. (1). Map of the James Bay study area on northwestern Santiago Island. Diamonds indicate locations of the 26 nests/territories with name codes next to each nest, and vegetation types: Arid (white), Transition (dashed), and Lava Fields (gray).

herbaceous plants; (2) transition zone with abundant shrubby and seasonal herbaceous vegetation particularly pegadilla (Mentzelia aspera) and various tree species such as Guayabillo (Psidium galapageium) and Muyuyo (Cordia lutea); and (3) in the south-western part of the bay, there are open fields of pahoe-hoe lava with scarce vegetation. Galapagos Hawk territories can be found in all three vegetation types (Fig. 1). Because of the striking differences between vegetation types, we considered them an important factor for our questions.

Between 1998 and 2009, we captured and individually banded 660 hawks (270 adults and 390 juveniles, 72 of which were banded as nestlings/fledglings on their natal territories) with aluminum bands containing unique numbers for individual identification. Of the 72 young hawks banded on their natal territories, 59 were banded during or before 2005 , and so would be old enough to gain entry into a breeding group by 2009. Hawks were caught with a rope and noose or using a bal-chatri trap with a Black Rat (Rattus rattus) as bait.

\section{Natal Dispersal}

We used individuals that were banded as nestlings/ fledglings on natal territories and then known to enter a territorial group later ( $\mathrm{n}=13$ individuals, representing $22 \%$ of nestlings/fledglings banded on natal territories by 2005). Each individual was considered as an independent observation.

To test whether juveniles tended to disperse as adults to territories neighboring their natal territories, for each of the 13 dispersers, we classified the 25 territories in our study area as neighboring or non-neighboring from the perspective of the disperser's natal site. We calculated the random probability of an individual settling in a neighboring (immediately adjacent to the natal territory) or non-neighboring territory (at least one territory away) as the proportion of neighboring territories and non-neighboring territories for each nest in the study area and then calculated global means that we used as probabilities of an individual entering either category of territory, assuming all territories are equally accessible to each individual. The classifications of the territories and their boundaries were based on the nest location and field observations of social interactions between territorial individuals. We used a chi-squared test to compare the number observed entering adjacent territories to the number expected by chance.

To analyze preferences of the 13 dispersers towards specific vegetation types similar to their natal areas, we 
classified each territory by their most conspicuous features, as either arid zone, transition zone or lava field. We calculated a random chance of entering a territory in each vegetation type based on the relative abundances of territories of different vegetation types, assuming all are equally accessible to each individual, and then used a chi-squared test to compare that expected value with the one observed. For both questions, we assumed no disperser would settle in its natal territory. Thus expectations differed slightly among dispersers, depending on the number of neighboring territories and the vegetation type of the natal territory.

We used ArcView 3.2 to measure dispersal distances of the 13 natal dispersal events. Distance was measured as a straight line from the natal nest to the nest belonging to the territorial group which the young hawk entered.

\section{Sociality}

Between 2005 and 2009, we counted floaters at two baiting sites in the James Bay study area [25], located in open areas where we put meat for 5 to 14 consecutive days in June-July (during the breeding season) to attract them. We conducted censuses every $30 \mathrm{~min}$ for at least 8 hours per day in the area surrounding the bait, recording the identities of all banded individuals visiting the bait, as well as the number and age class of banded and unbanded hawks. During 168 cumulative hours of scans at these baiting sites, we recorded 2900 observations of juvenile hawks of which 1030 (35.5\%) were banded, representing 103 different individuals of the 390 banded between 1998 and 2009.

We calculated the average visit time to the baiting site, and used the lower 95\% confidence limit as a standard time measure of association. To be scored as "together" on any specific day, a pair of individuals would have to have cooccurred for at least this standard association time. In case this definition of association was too strict, we also calculated the random probability of seeing two individuals together as the product of the proportion of bait-days when each bird was observed, without restrictions on the specific cooccurring time period. We calculated the probability of seeing each pair of individuals "together" by chance (expected value) as the product of the frequency of observation of each individual (based on [26]) and compared the expected value to the observed value using a chi-squared test. To calculate the power of our statistical test we used G*Power 3.0.10, calculating the size effect using Cramer's Phi (based on [26]).

\section{RESULTS}

\section{Natal Dispersal}

Natal territory and first adult breeding territory are listed for each disperser in Table 1, with sex, banding year, first year seen as territorial adult, number of neighboring territories and number of territories with the same vegetation type. Natal dispersal distance ranged from 0.47 to $4.00 \mathrm{~km}$ (Mean $\pm \mathrm{SD}=1.72 \pm 1.09 \mathrm{~km}$ ) and dispersing birds entered a breeding territory at between three to nine years of age.

We found no relationship between vegetation zones of natal and breeding territories across the 13 individuals for which both locations were known $\left(X^{2}=7.654\right.$, df $=5$ $p=0.176$, power $=0.57)$. Dispersers were significantly more likely to enter a neighboring territory than expected by chance $\left(\mathrm{X}^{2}=3.992, \mathrm{df}=1, \mathrm{p}=0.045\right.$, power $\left.=0.32\right)$.

Table 1. Summary of Individuals Used in Study of Natal Dispersal Patterns. List Includes Sex (M=male, F=female); Year where the Individual was Banded as Fledgling or Nestling, and its Natal Territory; the Year when each Individual was First seen as Territorial and in which Territory it First Joined a Breeding Group. For each Disperser, the Distance between Natal and Breeding Territory, the Number of Immediate Neighboring Territories and Territories with the Same Vegetation Types inside the Study Area are Listed. An Asterisk Next to the Number Means that the Individual either Entered one of the Immediate Neighboring Territories, or entered a Territory with the Same Vegetation Type

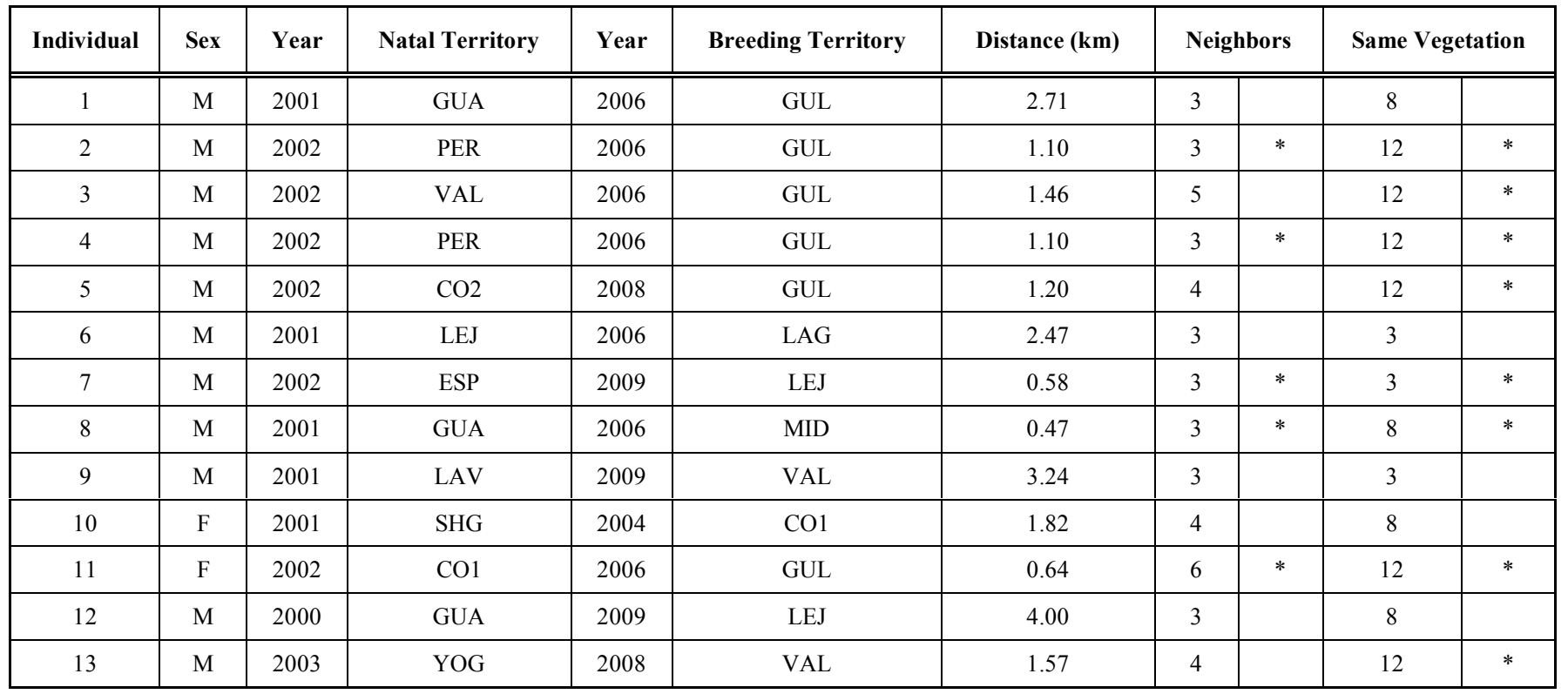




\section{Sociality}

We found no specific associations of floaters for any of the years $\left(2005, \mathrm{n}=10, \mathrm{X}^{2}=19.5, \mathrm{df}=44\right.$, power $=0.67$; $2006, \mathrm{n}=4, \mathrm{X}^{2}=1.775, \mathrm{df}=5$, power $=0.20 ; 2009, \mathrm{n}=21$, $X^{2}=150, d f=209$, power $\left.=0.999\right)$. We could not perform the analysis for 2007 and 2008 because of the absence of juveniles in those years. Due to the restrictions we used in our definition of "together", we were concerned about biasing our detection of coalitions. To address this possibility, we conducted a similar analysis without any restriction and still found no difference from random association (2005, $X^{2}=3.92$, df $=44$, power $=0.13 ; 2006, X^{2}=3.075$, $\mathrm{df}=5$, power $=0.33 ; 2009, \mathrm{X}^{2}=22.9$, $\mathrm{df}=209$, power $=$ $0.34)$. We also tested differences in sex-related association patterns, and found no significant differences from random association (data not shown).

\section{DISCUSSION}

\section{Natal Dispersal}

We found that 13 natal dispersal events in the Galapagos showed significant tendencies to disperse to neighboring territories. Our sample size represents $22 \%$ of the individuals banded on natal territories at least 4 years prior to our analysis (and hence old enough to attempt to breed). Not having more individuals banded as nestlings/fledglings on natal territories and later detected as breeding adults may have two possible explanations. First, they might suffer a high mortality rate, which has been observed for this population, having return rates lower than $10 \%$ (Rivera et al. submitted). Second, young hawks are dispersing beyond the boundaries of our study area in James Bay, which is limited to the area that can be monitored by foot.

The dispersal distance of less than $4 \mathrm{~km}$ suggests a certain degree of philopatry to the James Bay area. Studies of gene flow indicate that there is negligible gene flow among Galapagos Hawk populations on different islands [27], and our finding of such restricted dispersal distances could explain why hawks have not re-established breeding populations on the four islands where they have become extinct.

Our results suggest that hawks do tend to disperse to neighboring territories, but social and demographic characteristics may influence the chances for a hawk to enter a breeding group. The strong bias in our sample in relation to sex (11 males and 2 females) may give important cues of sex related dispersal patterns. Given that approximately equal numbers of female and male fledglings were banded (data not shown), this bias may indicate (a) differential mortality, which is not apparent in the baiting sites census, as well as sex-related (b) differences in dispersal pressures and/or (c) behaviours. The polyandrous breeding system imposes very different challenges for males and females: males can join a group without displacing a male, since there can be several males per territory, but females must replace a current or former territorial female, given that there is only one female per breeding group. Thus it might be advantageous for females to disperse farther for an opportunity to breed, explaining the continuous gene flow reported across Santiago Island [27].
Finding significant natal dispersal to neighboring territories can be related to familiarity of the habitat, as found by Kauffman et al. [5]. However, in our case the parallel test for habitat preference was not significant $(p=0.134)$. The discrete vegetation classification may be too coarse to detect more specific attractive habitat features, or the explanation lies in social interactions that are still to be studied.

\section{Sociality}

Juvenile hawks moved in relatively casual aggregations and did not constitute stable coalitions involving particular individuals. Simple aggregation could be advantageous for participants, related to overwhelming territorial defenses or hunting efficiency. Parker et al. [20] and Margalida and Boudet [21] found that coalitions formed among relatives in Black Vultures and Egyptian Vultures, respectively. In the case of the Galapagos Hawk, where successful nests commonly fledge only one, it is likely that hawks cannot recognize previously fledged siblings; therefore advantages related to kinship are unlikely. Galapagos hawks show a strong tendency as juveniles to gregariousness and tolerance of conspecifics, which foretells their later tendency to form stable groups as breeding adults. Again, the mechanism of group formation and individual choice for group admission remains unknown.

The fact that we did not find stable coalitions among juveniles differs from adult behavior, when they form cohesive and stable breeding groups. Differences may be related to the contrasting pressures that they face, floaters that do not breed and are more flexible in feeding opportunities, and breeding adults that are sedentary and breed annually. Understanding social behavior during this transitional stage, from juveniles to adults, will require further monitoring of this raptor species and its population dynamics, and will greatly contribute to understanding the switch in social behaviors related to life history.

\section{ACKNOWLEDGEMENTS}

We thank all the people who have contributed in different ways to the Galapagos hawk project since 1998, particularly Jenny Bollmer, Ken Levenstein, Noah Whiteman, Freddy Cabrera, Tjitte DeVries, Pablo Sanchez, Paolo Piedrahita, Michelle Donaghy Cannon and Jim Bednarz. The manuscript was improved thanks to the comments of the UMSL faculty Zuleyma Tang-Martinez and Robert Ricklefs, and the people from the Parker Lab. This project was possible thanks to the funds provided primarily by The Peregrine Fund, with the long-term database supported as well by the Whitney R. Harris World Ecology Center, The Saint Louis Zoo's WildCare Institute, the National Science Foundation, and the Des Lee Collaborative Vision of UMSL and the Saint Louis Zoo.

\section{REFERENCES}

[1] Greenwood PJ, Harvey PH. The natal and breeding dispersal of birds. Ann Rev Ecol Syst 1982; 13: 1-21.

[2] Ronce O. How does it feel to be like a rolling stone? Ten questions about dispersal evolution. Ann Rev Ecol Evol Syst 2007; 38: 231 53. 
[3] Forero MG, Donazar JA, Hiraldo F. Causes and fitness consequences of natal dispersal in a population of black kites. Ecology 2002; 83: 858-72.

[4] Suarez S, Balbontin J, Ferrer M. Nesting habitat selection by booted eagles Hieraaetus pennatus and implications for management. J App Ecol 2000; 37: 215-23.

[5] Kauffman MJ, Pollock JF, Walton B. Spatial structure, dispersal, and management of a recovering raptor population. Am Nat 2004; 164: 582-97.

[6] Whitfield DP, Duffy K, McLeod DRA, et al. Juvenile dispersal of white-tailed eagles in western Scotland. J Rapt Res 2009; 43: 11020 .

[7] Kenward RE, Marcström V, Karlbom M. Demographic estimates from radio-tagging: models of age-specific survival and breeding in the goshawk. J Anim Ecol 1999; 68: 1020-33.

[8] Kenward RE, Walls SS, Hodder KH. Life path analysis: scaling indicates priming effects of social and habitat factors on dispersal distances. J Anim Ecol 2001; 70: 1-13.

[9] Struwe-Juhl B, Grünkorn T. Results of colour-ringing white-tailed sea eagles Haliaeetus albicilla in schleswig-holstein: site fidelity, movements, dispersal, age of first breeding, age structure and breeding of siblings. Vogelwelt 2007; 128: 117-29.

[10] van Balen S. Tropical forest raptors in Indonesia: recent information on distribution, status, and conservation. J Rapt Res 1998; 32: 56-63.

[11] Rafanomezantsoa S, Watson RT, Thorstrom R. Juvenile dispersal of Madagascar fish-eagles tracked by satellite telemetry. J Rapt Res 2002; 36: 309-14.

[12] Nijman V, van Balen S. Wandering stars: age-related habitat use and dispersal of Javan Hawk-eagles (Spizaetus bartelsi). J Ornithol 2003; 144: 451-8.

[13] Cody ML. Habitat selection in birds. Academic Press: New York 1985.

[14] Teuschl Y, Taborsky B, Taborsky M. How do cuckoos find their host? The role of habitat imprinting. Anim Behav 1998; 56: 142533.
[15] Tonnis B, Grant PR, Grant BR, Petren K. Habitat selection and ecological speciation in Galapagos warbler finches (Certhidea olivacea and Certhidea fusca). Proc R Soc B 2005; 272: 819-26.

[16] Faaborg J, Parker PG, DeLay L, et al. Confirmation of cooperative polyandry in the Galapagos Hawk (Buteo galapagoensis) using DNA fingerprinting. Behav Ecol Sociobiol 1995; 36: 83-90.

[17] Parker PG. A most unusual hawk: One mother and several fathers. In: Tui de Roi, Ed. Galapagos: preserving Darwin's legacy. Firefly Books: Ontario 2009; pp. 130-7.

[18] de Vries TJ. The breeding biology of the Galápagos hawk, Buteo galapagoensis. Le Gerfaut 1975; 65: 29-57.

[19] Rabenold PG. Family associations in communally roosting. Black Vultures. Auk 1986; 103: 32-41.

[20] Parker PG, Waite TA, Decker MD. Kinship and association in communally roosting black vultures. Anim Behav 1995; 49: 395401.

[21] Margalida A, Boudet J. Dynamics and temporal variation in age structure at a communal roost of Egyptian vultures (Neophron percnopterus) in northeastern Spain. J Rapt Res 2003; 37: 252-6.

[22] Galeotti P, Tavechia G, Bonetti A. Homerange and habitat use of long-eared owls in open farmland (Po Plain, Northern Italy), in relation to prey availability. J Wildl Res 1997; 2: 137-45.

[23] Penteriani V, Otalora F, Ferrer M. Floater survival affects population persistence. The role of prey availability and environmental stochasticity. Oikos 2005; 108: 523-34.

[24] Jackson MH. Galápagos: a natural history. Canada: University of Calgary Press 1993.

[25] Parker PG. 2005-2009 Survey of Galapagos Hawks (Buteo galapagoensis) on Islas Santiago and Espanola, Galapagos, Ecuador. Rep Galapagos Nat Park 2009; pp. 19.

[26] Zar J. Biostatistical analysis, $4^{\text {th. }}$ ed. Simon \& Shuster, Upper Saddle River: New Jersey 1999.

[27] Bollmer JL, Whiteman NK, Bednarz JC, DeVries T, Parker PG. Population genetics of the Galapagos hawk (Buteo galapagoensis): genetic monomorphism within isolated populations. Auk 2005; 122: $1210-24$.

\author{
Received: November 25, 2010 \\ Revised: January 18, 2011 \\ Accepted: January 19, 2011 \\ (C) Rivera et al.; Licensee Bentham Open.
}

This is an open access article licensed under the terms of the Creative Commons Attribution Non-Commercial License (http://creativecommons.org/licenses/by$\mathrm{nc} / 3.0 /$ ), which permits unrestricted, non-commercial use, distribution and reproduction in any medium, provided the work is properly cited. 